\title{
Traffic Conflict Modelling at Six Leg Unsignalized Intersection
}

\author{
Purnawan and Febrian Qadri
}

\begin{abstract}
Traffic conflicts at six leg unsignalised intersection could produce traffic accident, this is because of complex traffic interaction in this area. This paper describes the result of analysis and modelling on traffic conflict at six leg unsignalised intersection. The data was captured using handycam, and extracted using video playback and traffic logger. From the analysis, it shows that traffic volume at this intersection is still relatively low, however, the number of conflicts is relatively high. This is because of high number variation of traffic manoeuvres from six intersection leg, and the wide area at conflict zone produce high variation of traffic manoeuvres. The majority traffic conflict type at the site is crossing. From the analysis of time to accident and vehicle speed, it shows that majority conflict type is non-serious conflict. These conflicts have been modelled using multi-regression linier, traffic volume and average traffic speed are used as the independent variables.
\end{abstract}

Index Terms - traffic conflict, modelling, intersection

\section{INTRODUCTION}

$\mathrm{U}$ NSIGNALIZED intersection is a location that potential accident occurred, vehicles will conflict at several conflict point locations at intersection. The performance of drivers crossing at intersection is affecting by traffic flow and intersection environment conditions. High traffic volume would increase more accident potential because frequency of traffic conflict will increase. Another factor that has contribution to increasing the number of traffic conflict is the number of intersection leg. Increasing the number of intersection leg would also increase potential of traffic conflict because the number of traffic conflict location is increasing. There is previous extensive study on traffic conflict, Zang et al stated that there are fundamental issues of the ambiguity and inconsistency in traffic conflict framework in the previous study [1]. Hyden explained potential of traffic conflict in the safety pyramid, the bottom of pyramid is undisturbed passages, it is a state where vehicle traffic is running as usual, then potential conflict, in this condition traffic at the intersection of potential conflict but has not occurred. This condition followed by slight conflict, it is the situation where two or more vehicles are approaching each other but still can avoid and distance still far enough distance or still can make

We thank Febrian and laboratory assistant for survey and extract the data, so this research could be finished.

Purnawan is with Andalas University, Padang, West Sumatera, Indonesia. $\mathrm{He}$ is now with the Department of Civil Engineering, Andalas University, West Sumatera. (e-mail: purnawan@gmail.com).

Febrian Qadri is with Andalas University, Padang, West Sumatera, Indonesia. He is now with the Department of Civil Engineering, Andalas University, West Sumatera. braking. Then, serious conflict is two or more vehicles approaching each other shortly before the accident occurs and the distance is very small avoid can braking to stop or move lane. An accident is an unexpected and accidental circumstance that can result in casualties as well as material losses. In order to reduce traffic conflict effect, Hyden developed Traffic Conflict Technique (TCT) method, this method is used to improve traffic safety. Basic principle of this method is to identify near-missed accidents that are closely related to accidents [2]. This method was developed by the Department of Traffic Planning and Engineering at Lund University in Sweden. Application of this method is not only in developed countries but also developed throughout the world. This TCT method has been applied in Europe, especially in Scandinavian countries. This method also has been introduced in Uganda, Tanzania, South Africa, Thailand, Sri Lanka, Jordan, Turkey, Costa Rica, Jamaica, Brazil and Bolivia [3].

Traffic conflict at unsignalized six leg intersection have unique characteristic, high number of intersection leg and unregular intersection design produce high traffic conflict with various diffferent manouvres. This condition has potential to inflict accident for driver. This study to explore the traffic conflict characteristic at unsignalized six leg intersection and developing model of traffic conflict. The method developed by Hyden and Lawalata was adopted to measure traffic conflict characteristic [1][4].

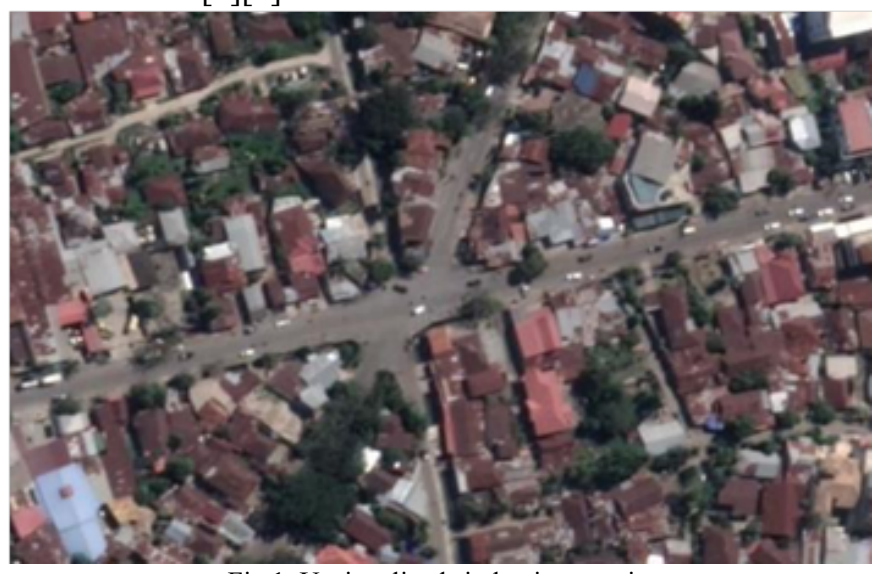

Fig 1. Unsignalized six leg intersection

\section{METHODOLOGY}

This research was conducted at unsignalized intersection in Padang, West Sumatera, Indonenesia, the intersection has six legs and a wide area of traffic conflict (see Fig. 1). Road widths at leg of intersection are about 4.5 to $10.0 \mathrm{~m}$. Traffic 
movement was captured using handycam. The type of traffic movement from each leg is shown in Fig. 2, traffic movement at each leg has similar patterns and directions. In order to capture traffic conflict, the survey was conducted on Monday during high traffic volume in the morning (6.00-9.00), afternoon (11.00-13.00) and evening (15.00-18.00). The interaction vehicles during traffic conflict were captured using handycam that is installed at intersection. This survey was conducted for about 9 hours.

Traffic conflict data was extracted using video playback and data logger [4]. Type and frequency of traffic conflicts were identified, and then the manoeuvres of conflicts were classified. Time and speed of vehicles movement before conflict were measured, then classifications of serious and non-serious conflicts were determined based the method developed by Heyden [2]. In order to identify the location of traffic conflict, the area of conflict was devided into small areas as shown in Fig. 3. From this devided area, it could identify the location of high traffic conflict or high potential of accident. Traffic conflic model was developed based on extracted data, the model was developed using linier regression approach.

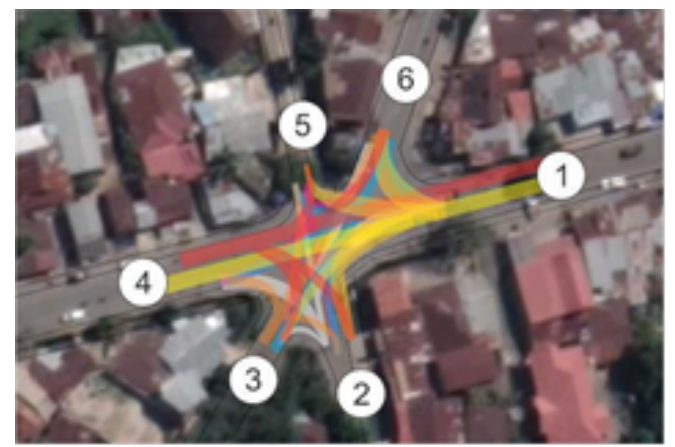

Fig 2. Traffic movement at six legs unsignalised intersection

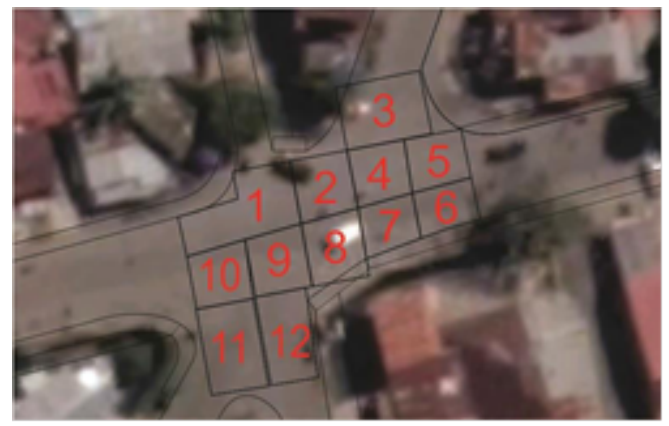

Fig 3. Segment for traffic conflict identification

\section{RESULT AND DISCUSSION}

\section{A. Traffic conflict type}

From data extraction, there are 418 traffic conflicts are identified. Those conflicts can be classified into 3 types, i.e. crossing, merging and weaving. The high frequency of traffic conflicts type is crossing, and the lowest one is weaving traffic conflict. The number of traffic conflict is shown in Fig. 4.

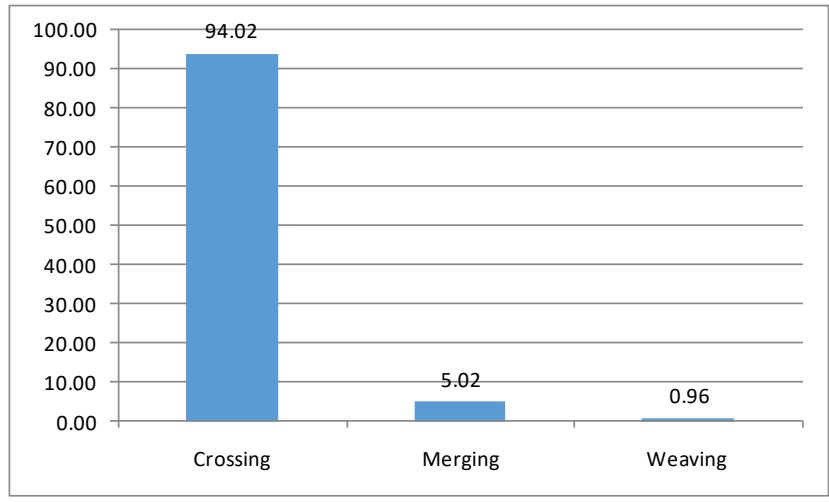

Fig 4. Distribution of traffic conflict types

\section{B. Driver response to traffic conflict}

Driver reactions to traffic conflict vary, depending on the traffic conditions. Types of driver response movement could be classified into 4 responses, i.e (1) evasive, (2) evasive speed up, (3) brake, (4) brake - evasive. First, drivers would evasive the conflict when they still have enough space for evasive manoeuvre. Second, drivers would evasive and speed up if the speed of vehicle is not low and enough to speed and the drivers have space to speed up the vehicle, third condition, drivers would break the vehicle when they did not have the space for moving, so the drivers will stop the vehicle, wait until front vehicle moving. The fourth conditions occur when there is enough space for force manoeuvre then stop vehicles, wait until front vehicle moving. The distribution of drivers response can be seen in Fig. 5.

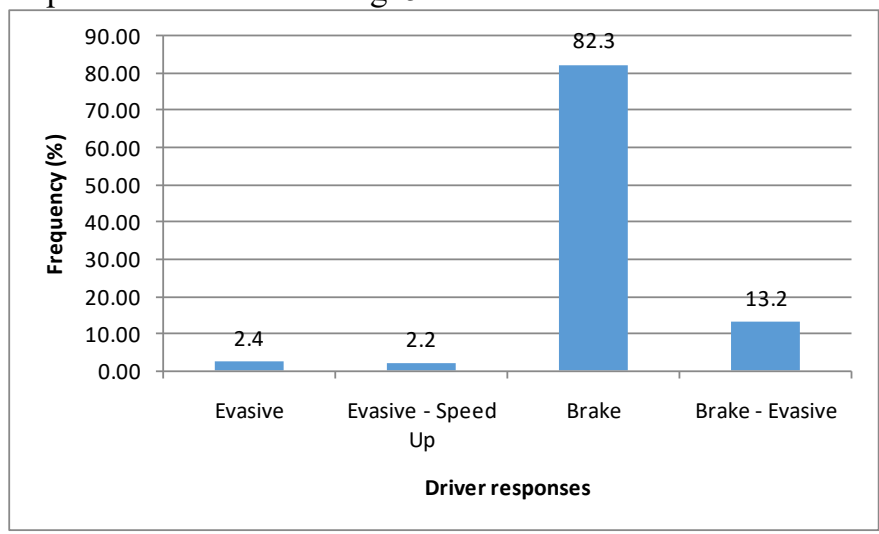

Fig 5. Driver response to traffic conflict

Fig.5 shows that most drivers break the vehicles to decelerate the speed, this is conducted to avoid conflict with opponent vehicle. There are several drivers still try to evasive conflict with opponent vehicles, but it is not high. They do the evasive movement because there is space to evasive maneuvers.

\section{Vehicle near to Confiict}

Another factor that affects the conditions of traffic conflict is vehicle speed, this speed will affect the serious or non-serious conflict type. 


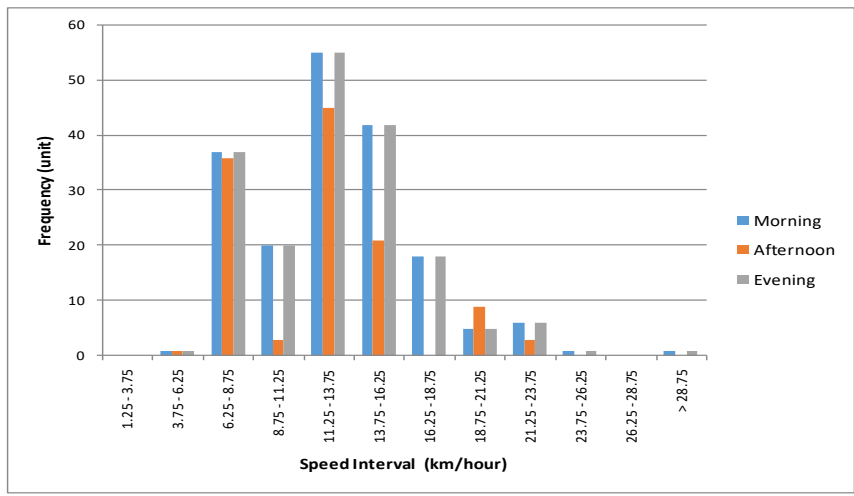

Fig. 6. Vehicle speed approaching conflict

From collected data in the peak hour morning, afternoon and evening, the speed of vehicle during moving to conflict are recorded, the distribution of that speed are shown in Fig. 6 . This figure indicates that vehicle speed to conflict is mostly about $6-18 \mathrm{~km} / \mathrm{hr}$, the sample of vehicle speed at afternoon are relatively low compared other survey time, it is because the traffic volume at that time is relatively low, therefore the number of conflicts is also low.

\section{Condition of vehicle conflict type}

Conflict of vehicles would have consequences to the drivers or vehicles, the consequences are classified into serious and non-serious conflict. Serious conflict is the conflict condition that would result a breakdown in the interaction between the road user, environment and vehicle, and non-serious conflict is opposite condition of serious conflict. Traffic conflict classification is determined based on the vehicle speed and time to accident [2]. Factors causing traffic conflict that has potential to inflict an accident at this intersection are :

1) Internal factors

a. Motorists who drive their vehicles fast enough.

b. The riders do not move on the right track.

c. Some pedestrians are crossing the middle of an intersection.

2) External factors

a. Simple geometric conditions that harm the rider.

b. Absence of road markings, directions and traffic signs at this intersection

c. Failure of traffic lights.

d. Geometric conditions on Bandar Karam Island roads make it difficult to see other riders from different directions.

e. The presence of public transport that stops then boarding and un-boarding passengers at the legs of the intersection

f. High traffic volume during peak hours

3) Environmental factors

The existence of an illegal motorcycle at the middle edge of the intersection causing vehicles manoeuvre to different path.

Based on data analysis using Hyden method [2], the distribution of vehicle conflict conditions is classified into serious conflict and non-serious conflict. Figure 7 shows the result of the classification of the data. It is shown that majority of vehicle conflict at the condition non-serious conflict, people drive the vehicle at relatively low speed and have enough time to response the situation. If the speed of vehicle is high, it will result in high degree of conflict and accident [5]. From this figure, it is easy to identify the traffic conflict that potential to accident. This method has advantages to identify the potential of accident directly from observed data, then it can be concluded fast [6]. Hyden recommends that we do not have to wait for accident for improving road environment and traffic management, traffic behaviour will give clue for improving road safety at intersection [7].

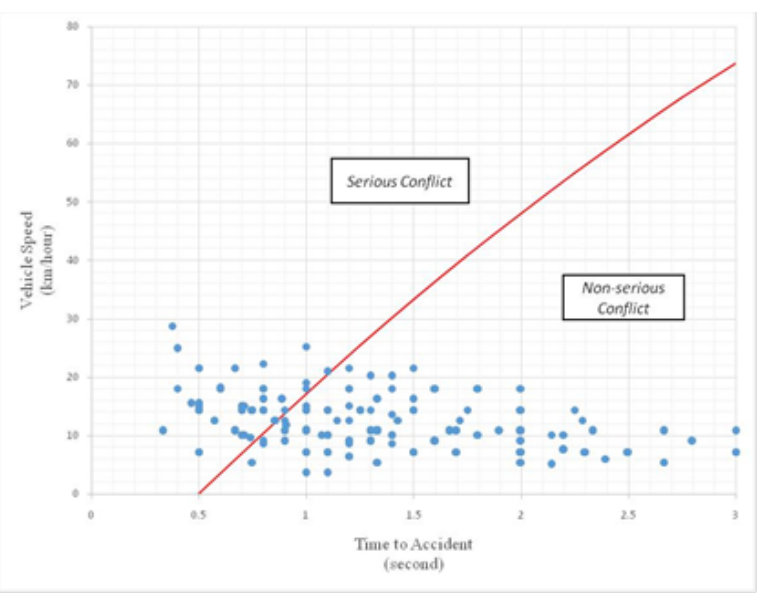

\section{E. Traffic Conflict Modelling}

Traffic conflict model at signalized using generalized linear models approach have been developed by Essa dan Sayed, this model use traffic volume, maximum queue length and shock wave speed and platoon ratio as model parameters [8]. Saied and Said developed traffic conflict model using loglinear approach, this model for traffic conflict at uncontrolled intersection, the independent variables of model are the number of legs, road segregation and traffic direction [9]. In this study, traffic conflict model was developed using linear regression approach, three independent variables were used to model of traffic conflict, it is traffic volume, motorcycle of volume and average traffic speed. It is determined based on simplicity during data collection and analysis. From statistical analysis, the best model has been achieved using two variables, i.e. traffic volume $\left(\mathrm{X}_{1}\right)$ and average traffic speed $\left(\mathrm{X}_{2}\right)$. The developed model is as equation 1 .

$$
\mathrm{Y}=-57.947+0.014 . \mathrm{X}_{1}+5.822 . \mathrm{X}_{2}
$$

$(\mathrm{t}=2.143) \quad(\mathrm{t}=1.247) \quad \mathrm{R}^{2}=0.447$

$(\mathrm{P}-\mathrm{val}=0.076) \quad(\mathrm{P}-\mathrm{val}=0.259)$

Although this model has not enough strong relationship between variable dependent and independent, it still can be used to predict the number of traffic conflict using variable input traffic volume and average traffic speed.

\section{CONCLISSION}

Unsignalized six leg intersection could become a dangerous intersection if the behaviour of traffic is uncontrolled. From the result of analysis, the traffic volume at this intersection could be classified as low traffic. At this intersection, crossing 
traffic conflict is the highest, and the lowest is weaving traffic conflict. Majority of the conflicts at this intersection are nonserious conflict, this is because the vehicle conflict at low speed (5-20 km/hour) and time to accident more than 1 second. This conflict could be modelled using two independent variable, traffic volume and average traffic speed. From validation process, the model could produce similar result compared collected data, this model could be used to predict the number of traffic conflict in the future.

\section{REFERENCES}

[1] L. Zeng, K. Ismail, and X. Meng, NRC Research Press, 2014 www.nrcrearchpress.com

[2] C. Hydén, Bulletin Lund Institute of Technology Department, Issue Number 70, Department of Traffic Planning and Engineering, Lund Institute of Technology, University of Lund, Sweden, 1987

[3] S. Almqvist., and L. Ekman. The Swedish Traffic Conflict Technique: Observation Manual, Department of Technology and Society Traffic Engineering, Lund University, 2001

[4] Lawalata, Greece Maria, and Heddy Rohandi Agah. "Traffic conflict analysis as a road safety diagnostic tool for urban road facilities." International Journal of Technology 2.2: 112-121, 2011

[5] S.T.M.C, Janssen, Institute for Road Safety Research SWOV, The Netherlands, 1985

[6] A. Laureshyn and A. Varhelyi, The Swedish Traffic Conflict TechniqueObserver Manual, Lund University, 2018

[7] C., Hyden, Proceeding $29^{\text {th }}$ ICTCT conference, 21 October, Lund, 2016

[8] Essa, Mohamed, and Tarek Sayed. "Traffic conflict models to evaluate the safety of signalized intersections at the cycle level." Transportation research part C: emerging technologies 89: 289-302, 2018.

[9] A.M. Saied and G.M. Said, Proceeding of the Conference Road Safety on Three Continent, 19-21 September, Moscow, 2001 